\title{
Phase Angle Control Method of Speed Control of Single Phase Induction Motor
}

\author{
M. Narayanan ${ }^{1}$, R. Vidhya ${ }^{2}$, P.Yuvaraj ${ }^{3}$ \\ Assistant Professor, Department of EEE, INFO Institute of Engineering, Coimbatore, Tamilnadu, India ${ }^{1,2}$ \\ Assistant Professor, Department of EEE, PPG Institute of Technology, Coimbatore, Tamilnadu, India ${ }^{3}$
}

\begin{abstract}
The study of power electronic converters is vital to gain knowledge on Variable Speed Drives or Energy Efficient Drives. Induction motors are the load which contributes to about $70 \%$ of total loads used in the world. Variable speed drives are employed for industrial processes and in many applications. In this paper ac - ac voltage controller is used to vary the input voltage to control the speed of the induction motor. The effect of harmonics and Total Harmonic Distortion (THD) is also studied in this paper.
\end{abstract}

Keywords: AC - AC voltage controller, Phase Angle Control, Capacitor start induction motor, Total Harmonic Distortion.

\section{INTRODUCTION}

Induction motors have replaced DC drives in many applications due to its rugged construction, cost effectiveness. Its application varies from domestic such as washing machine, pumps, refrigerators, etc. to industrial applications such as industrial robots, electric vehicles, elevators and so on.

To obtain energy efficiency instead of running machines at a constant speed, speed control method is used. The conventional speed control methods suffer from various disadvantages like mechanical wear and tear, frequent maintenance requirement, less efficient and bulky. Therefore the use of power electronic devices and controllers play a vital role it improving the above factors and also help them in soft starting.

To achieve this simple and compact power electronic controller circuit called AC voltage controller is connected between the input ac supply and the load (single phase induction motor). The controller posses two antriparallel SCR's to regulate the supply voltage to the load. The output voltage of this converter can be varied by varying the firing angle of the thyristor used [8]. There are two control strategies by which the output voltage can be varied [1]. They are:

a) On - Off cycle control

b) Phase angle control or Firing angle control

In On - Off cycle control method the input AC supply is kept ON for say ' $n$ ' of cycles and OFF for ' $m$ ' number of cycles. During the OFF period the sudden voltage variations should be withstand by the load and the power electronic devices used.

Hence in this paper firing angle control is used to control the speed of the induction motor.

\section{AC VOLTAGE CONTROLLER}

Fig.1 shows the circuit diagram of two SCR's connected in anti - parallel to control the output voltage and hence the speed of the induction motor. The gate pulse or the firing pulse can be varied by using Pulse Width

Modulation (PWM) technique and hence the rms output voltage and performance such as speed, torque can be studied [4] and the effect of dominant harmonics present, $\%$ THD can be studied.

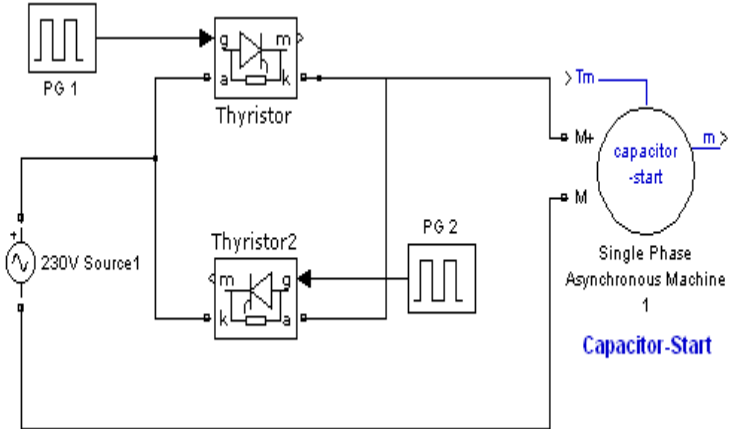

Fig. 1. Circuit Diagram

\section{SPEED CONTROL}

Speed control is the method by which the speed of the machine is varied purposely by varying either the stator or rotor parameter to satisfy the load demand and to improve the efficiency of the drive. Speed control of induction motor can be carried out both from stator side such as varying the supply voltage, frequency, number of poles, etc. and from the rotor side which includes varying external resistance connected in the rotor circuit, cascade control, etc.

In this paper speed control of induction by varying the supply voltage is performed. The voltage varying technique affects the performance of three phase induction motor badly whereas it is effective in the case of single phase induction motor.

\section{PHASE ANGLE CONTROL}

In this method, the output voltage is controlled by triggering the SCRs $\mathrm{T} 1$ and $\mathrm{T} 2$. By varying the firing angle the rms value of output voltage is varied [3]. Since the sine wave pattern is getting changed, harmonics will be introduced in the system and hence \% THD will get increased. 
The expression for rms value of output voltage for contents. From the figure, the dominant harmonics which resistive load is given by:

$$
V o(r m s)=V s \sqrt{\frac{(\Pi-\alpha)+(\sin 2 \alpha) / 2}{\Pi}}
$$

where, $V s=\frac{V m}{\sqrt{2}}=$ RMS Value of input supply voltage

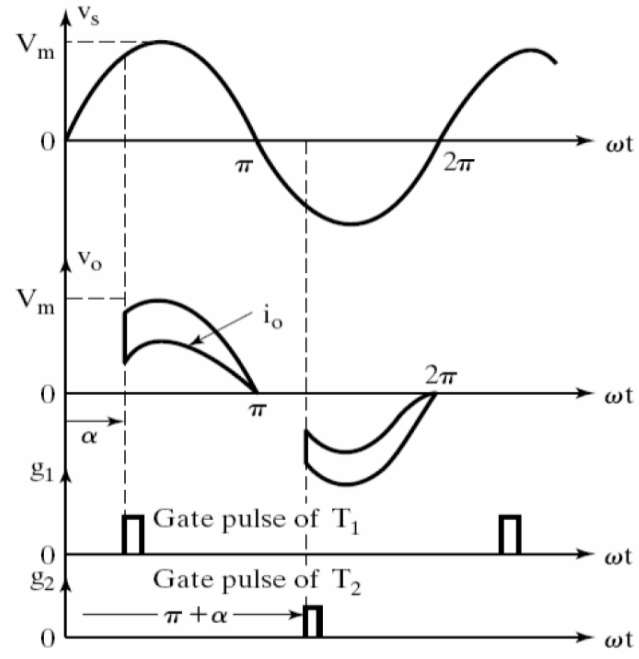

Fig. 2. Input and output waveforms

The advantage of this method is the load voltage variation is smooth but since the pattern of the input waveform is varied harmonics will be introduced in the system.

\section{HARMONICS}

Harmonics are frequencies present in the output waveform other than the fundamental. If fundamental is $50 \mathrm{~Hz}$, then its integral multiple ie., $100 \mathrm{~Hz}, 150 \mathrm{~Hz}, 200 \mathrm{~Hz}, 250 \mathrm{~Hz}$, and so on are said to be the harmonic frequency. The study of the frequencies other than the fundamental is necessary why because it leads to poor power factor, electromagnetic interference, heating of machines and degrade the performance of the machine. Therefore the study of each and every harmonic order is necessary to identify the dominant harmonics present in the system and to use suitable techniques to reduce the \% THD.

As per the IEEE standards the \% THD limit in the voltage waveform is $5 \%$ [7]. So designing a system to control the required parameters along with maintain the \% THD level with limits helps in obtaining an efficient control and improves the life time of the machine.

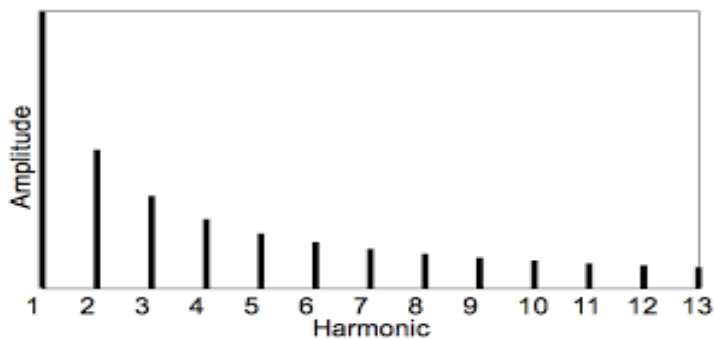

Fig. 3. Harmonic spectrum

The above diagram shows the variation of amplitude with respect to the harmonic order. The harmonic order 1(say $50 \mathrm{~Hz})$ is the fundamental where as the remaining orders such as $2(100 \mathrm{~Hz}), 3(150 \mathrm{~Hz})$ and so on are the harmonic have higher magnitude and the less dominant harmonics can be viewed.

\section{CAPACITOR START INDUCTION MOTOR}

For small power applications (less than $2 \mathrm{KW}$ ), the use of single phase induction plays a dominant role both in domestic and in industrial application. Moreover the supply (single phase) is readily available even in remote areas. The single phase induction motor is not self starting and hence the winding is splited into two as main and auxiliary winding which are 90 degrees electrically displaced. There are three types of single phase induction motor. They are:

a) Split phase induction motor

b) Capacitor induction motor

c) Shaded pole motor

The capacitor start induction motor is the first type of split phase induction motor. A split-phase motor whose auxiliary winding when connected with a capacitor in series becomes a capacitor start induction motor. This configuration helps to improve the starting torque and the power factor of the induction motor. Application of capacitor start motors are Compressors, fans, air conditioners, grinders, blowers.

\section{MAIN WINDING}

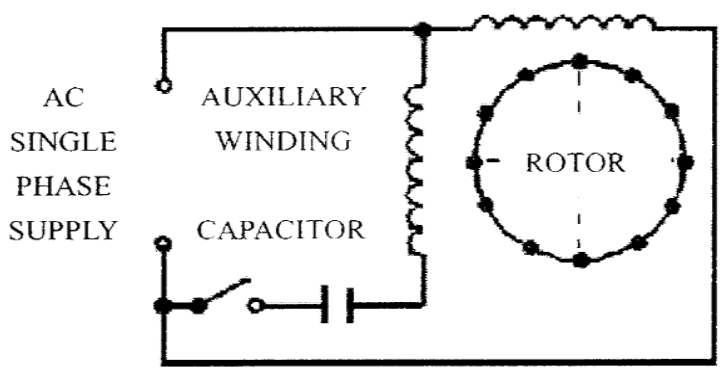

Fig. 4. Capacitor Start induction motor

VII. MATLAB SIMULATION

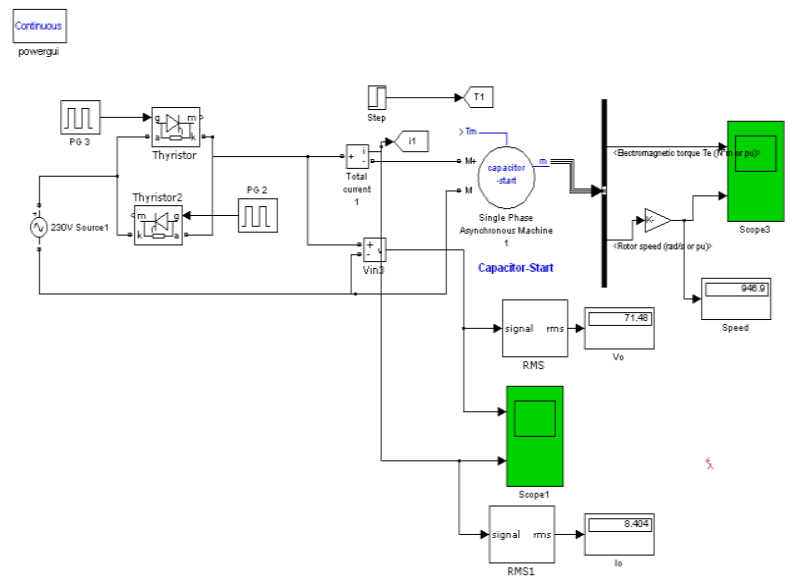

Fig. 5. MATLAB simulation circuit

Fig. 5 shows the circuit diagram of two antiparallel SCR's acting as voltage regulator. Capacitor start induction motor is the load whose speed needs to be controlled. The phase angle control method is used to control the rms output voltage and hence the speed of the induction motor. 
$\%$ THD for various firing angle is noted to view the magnitude of the dominant harmonics present.

\section{CAPACITOR START INDUCTION MOTOR PARAMETERS:}

Nominal voltage : $230 \mathrm{~V}$

Frequency : $50 \mathrm{~Hz}$

Nominal power : $0.25 * 746 \mathrm{VA}$

Disconnection speed : $75 \%$ of synchronous speed

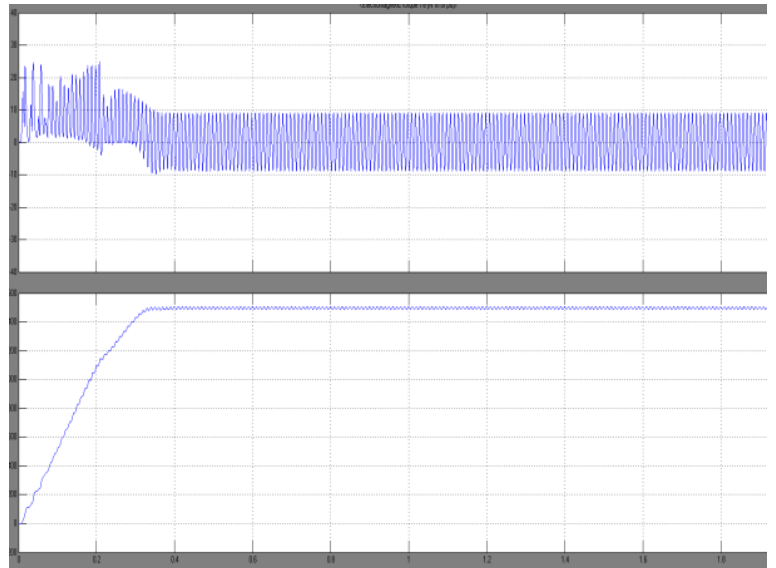

Fig. 6. No load electromagnetic torque and rotor speed for firing angle $=90$ degrees

The above figure shows the electromagnetic torque developed and rotor speed for firing angle = 90 degrees and on no load. The speed reaches to its steady state at time $\mathrm{t}=0.32 \mathrm{sec}$ and the torue is pulsating with a magnitude of $10 \mathrm{Nm}$ maximum.

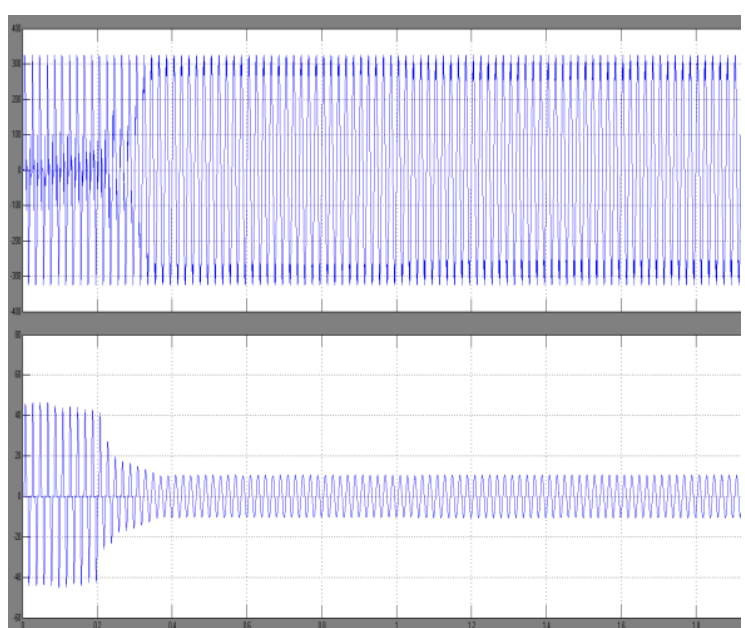

Fig. 7. Output voltage and current waveform for firing angle $=90$ degrees

Fig. 7 and 8 shows the output voltage, current and FFT analysis (harmonic spectrum) respectively when the motor is loaded with a torque of $1 \mathrm{Nm}$ at time $\mathrm{t}=1 \mathrm{sec}$. From the output current waveform it is clear that the auxiliary winging gets disconnected at time $\mathrm{t}=0.2 \mathrm{sec}$ after which the motor runs with the main winding current.

From the FFT analysis the \% THD is $67.91 \%$ and the $3^{\text {rd }}$, $5^{\text {th }}$ and $7^{\text {th }}$ harmonics are dominant in nature. Hence a suitable filter needs to be designed to eliminate these harmonics and to bring down the \%THD within standards.

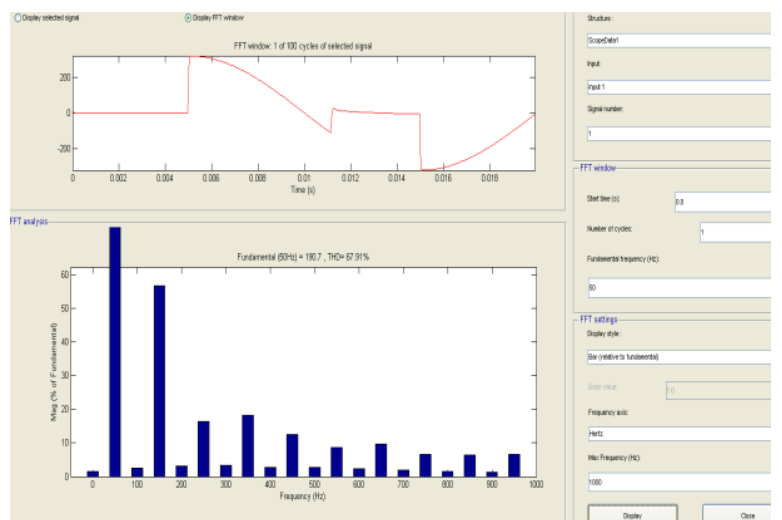

Fig. 8. FFT analysis for firing angle $=90$ degrees

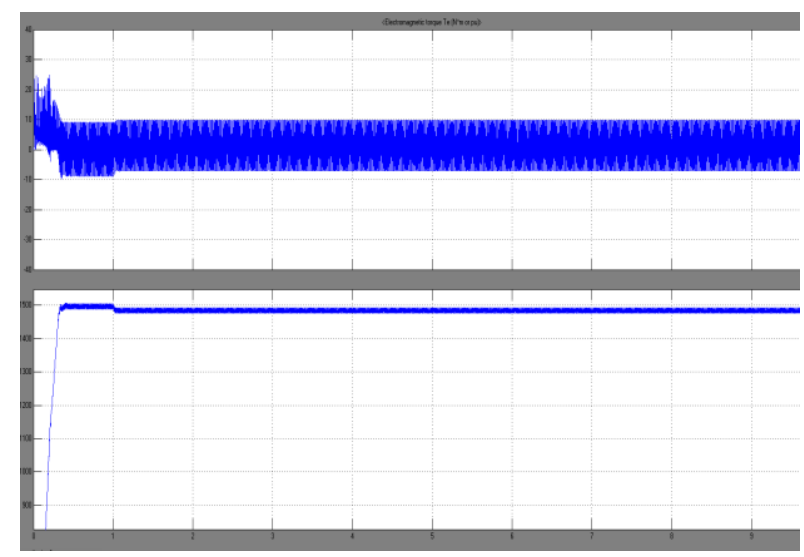

Fig. 9: Electromagnetic torque and rotor speed at load for firing angle $=90$ degrees

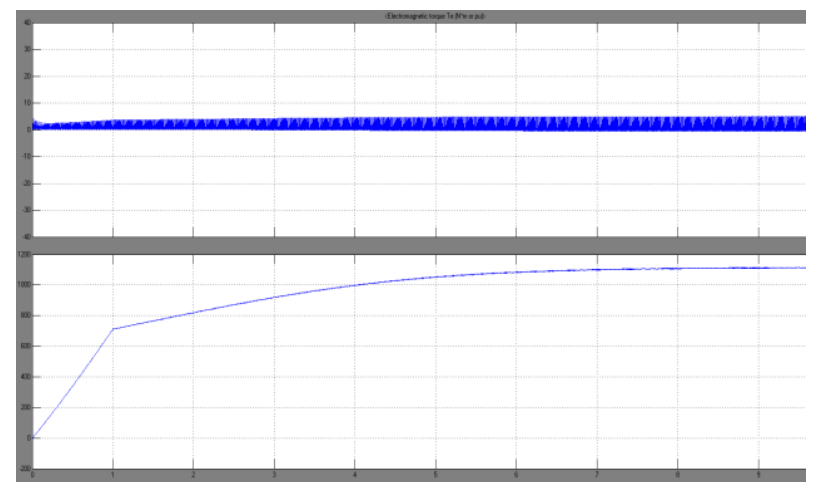

Fig. 10: Electromagnetic torque and rotor speed at load for firing angle $=135$ degrees

Fig. 9 and 10 shows the attainment of steady state speed for different firing angles. The time required to reach steady state speed increases as the firing angle increases.

Table 1 and 2 gives the information about variation of speed, rms output voltage and current, \% THD on no load and load for different firing angles. As the firing angle increases the rms output voltage decreases and the \% THD increases. The output voltage rms and \% THD is almost the same whether the machine is loaded or not since they do not depend on the load.

The table also shows the rms output voltage do not vary a much till firing angle is less than 90 degrees. This is due to the load inductance. The speed can be varied widely for firing angles greater than 110 degrees. 
TABLE 1 : NO LOAD VALUES FOR VARIOUS FIRING ANGLES

\begin{tabular}{|c|c|c|c|c|c|}
\hline $\begin{array}{c}\text { S. } \\
\text { No }\end{array}$ & $\begin{array}{c}\alpha \text { in } \\
\text { deg }\end{array}$ & $\begin{array}{c}\text { Vo rms } \\
(\mathbf{V})\end{array}$ & $\begin{array}{c}\text { Io rms } \\
(\mathbf{A})\end{array}$ & $\begin{array}{c}\text { Speed } \\
(\mathbf{r p m})\end{array}$ & \% THD \\
\hline 1 & 0 & 229.7 & 6.67 & 1506 & 0.31 \\
\hline 2 & 30 & 229.7 & 7.37 & 1506 & 14.65 \\
\hline 3 & 60 & 229.7 & 7.37 & 1506 & 39.35 \\
\hline 4 & 90 & 225.5 & 7.2 & 1505 & 67.92 \\
\hline 5 & 120 & 182.6 & 6.2 & 1501 & 112.18 \\
\hline 6 & 125 & 168 & 5.84 & 1500 & 122.15 \\
\hline 7 & 130 & 90.8 & 4.63 & 1377 & 134.47 \\
\hline 8 & 135 & 71.4 & 8.4 & 946.9 & 145.02 \\
\hline
\end{tabular}

\section{TABLE 2 : LOADED VALUES FOR VARIOUS} FIRING ANGLES

\begin{tabular}{|c|c|c|c|c|c|}
\hline $\begin{array}{c}\text { S. } \\
\text { No }\end{array}$ & $\begin{array}{c}\boldsymbol{\alpha} \text { in } \\
\text { deg }\end{array}$ & $\begin{array}{c}\text { Vo rms } \\
(\mathbf{V})\end{array}$ & $\begin{array}{c}\text { Io rms } \\
(\mathbf{A})\end{array}$ & $\begin{array}{c}\text { Speed } \\
(\mathbf{r p m})\end{array}$ & \% THD \\
\hline 1 & 0 & 229.6 & 7.37 & 1493 & 0.31 \\
\hline 2 & 30 & 229.6 & 7.37 & 1493 & 14.65 \\
\hline 3 & 60 & 229.6 & 7.37 & 1493 & 39.35 \\
\hline 4 & 90 & 221.4 & 7.13 & 1491 & 67.92 \\
\hline 5 & 120 & 157 & 5.64 & 1471 & 111.26 \\
\hline 6 & 130 & 81.91 & 9.8 & 1116 & 134.47 \\
\hline
\end{tabular}

where,

$\alpha \quad$ - Firing angle

Vorms - RMS value of output voltage

Iorms - RMS value of output current

\section{CONCLUSION}

The paper discusses the speed control of induction motor via ac voltage controller. Phase angle control method is used to control the output voltage and hence the speed. The load inductance limits the firing angle within a boundary where a wide range of speed control is possible. The \% THD increases as the firing angle increases. So a filter is needed to be designed to bring the \% THD within IEEE standards and to obtain energy efficiency.

\section{REFERENCES}

[1] Dharmesh.V.Khakhkhar, "Design and Simulation of Novel Integral Switching Cycle Control for Heating Load," International Journal of Emerging Trends in Electrical and Electronics, Vol. 5, Issue. 1, July2013.

[2] Rohit Gupta, Ruchika Lamba, and Subhransu Padhee, "Thyristor Based Speed Control Techniques of DC Motor: A Comparative Analysis, "International Journal of Scientific and Research Publications, Vol. 2, Issue 6, June 2012.

[3] E.S. Oluwasogo, and I.K. Okakwu, "Performance Analysis Of A Single-Phase Ac Voltage Controller Under Induction Motor Load," International Journal of Research in Engineering and Technology, Vol. 03, Issue: 06, Jun-2014.

[4] Dr. Jamal A. Mohammed," Speed Control of Single Phase Induction Motor Using Micro-Controller," ICIAC-12-13th April 2014.

[5] O. Oladepo and G.A. Adegboyega, "MATLAB Simulation of SinglePhase SCR Controller for Single Phase Induction Motor,

"International Journal of Electronic and Electrical Engineering, Vol 5, Number 2 (2012).

[6] R. P. Akabari, and Hitarth buch, "Modeling of split phase induction motor with single phase cycloconverter," Journal of Information, Knowledge and Research in Electrical Engineering," Vol. - 02, Issue - 02, Nov 12 To Oct 13

[7] Total Harmonic Distortion and Effects in Electrical Power Systems, Associated Power Technologies.
[8] Umar Farooq Siddiqui, Ajit Verma, and Shilpa Soni, "Comparative Performance Analysis of Induction Motor Using Semiconductor Devices in Terms of Firing Angle," International Journal of Emerging Technology and Advanced Engineering, Vol. 4, Issue 2, February 2014

[9] Devandra Kumar Shukla and Sudhanshu Tripathi, "Thyristor controlled power for induction motor," International Journal of Innovative Research and Studies, Vol. 2, Issue 7, July 2013.

\section{BIOGRAPHIES}

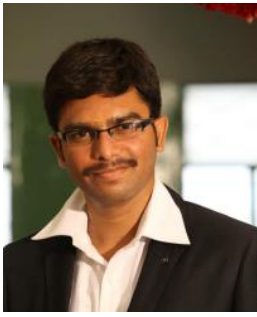

Mr. M. Narayanan, received his B. E. degree in 2008 in Electrical and Electronics Engineering from Karpagam College of Engineering Coimbatore, Anna UniversityChennai and M. E. in Power Electronics and Drives from Karpagam University, Coimbatore, Tamil Nadu, India in 2011. Presently he is working as Assistant Professor in Electrical and Electronics Engineering Department at Info Institute of Engineering, Coimbatore. His area of interests includes Inverters, Converters and Electrical drives and control.

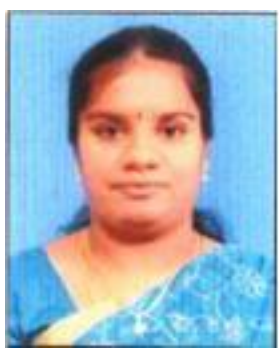

Ms. R. Vidhya is currently working as Assistant Professor (Senior Grade) in the Department of Electrical and Electronics Engineering, Info Institute of Engineering, Coimbatore, India. She received her B.E. degree in Electrical \& Electronics Engineering from Bharathiyar University, Coimbatore, India and M.E. degree from Anna University, Chennai, India. Currently she is pursuing her Ph.D in Anna University, Chennai. Her research interests include Power Electronics and Energy Engineering.

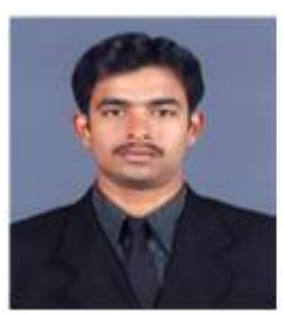

Mr. P. Yuvaraj is currently working as Assistant Professor in Department of Electrical and Electronics Engineering, PPG Institute of Technology, Tamilnadu, India. He received his B.E. degree in Electrical \& Electronics Engineering from Anna University, Chennai, India and M.E. degree in Power Electronics and Drives from Anna University, Coimbatore, India. His current research interests include DC-DC Power conversion and Multi-level inverter. 